\title{
Inflatable Device for Intraoperative Control Extension In Cervical Spine Surgery
}

\author{
Waleed A. Alsunbul, Almunder R. Algird, Mujeeb F. Sanjer, Kesava Reddy
}

Can J Neurol Sci. 2014; 41: 293-295

Anterior approach of the cervical spine surgery is an accepted procedure to treat various pathologies of the cervical spine. One of the keys to successful cervical spine surgery is an appropriate positioning, specifically appropriate degree of extension of the cervical spine. At times, the cervical spine extension may have to be altered intra-operatively, which make most of the products that are used to achieve cervical spine extension suffer from some disadvantages. The authors present a technical note regarding the use of a commonly available, reusable and inflatable device. The authors believe, it achieves the objectives of control extension of the cervical spine with no morbidity.

\section{Materials ANd Methods}

We describe the author's experience of utilizing the device in the anterior approach to the cervical spine. The inflatable device "Shoulder Float" was originally marketed for the purpose of pneumatic axillary support to provide even weight distribution of the patient on the operating table during epidural anesthesia (O.R. Comfort, LLC, USA). It measures 14.5 inches $(36.8 \mathrm{~cm})$ by 10.0 inches $(25.4 \mathrm{~cm})$. It is consisted of three main parts, the body, a three sided valve and a manual pump (Figure 1A \&B).

The device is placed under a supine patient prior to commencing intubation. The authors prefer to set it (Figure 2) so the upper border of the device is aligned with the shoulders and centred correctly in line with the neck. Alternatively, the device may be placed horizontally and directly behind the neck of the patient. The device is inflated to a desirable height to achieve controlled extension of the cervical spine. The inflation may be performed under lateral fluoroscopy if needed any time during the procedure.

\section{Results AND Discussion}

In most institutions, for the anterior approach to the cervical spine, standard devices such as pillows, folded blankets, intravenous fluid bags, bolsters or sand bags are used to achieve cervical spine extension ${ }^{1}$. The authors agree that these devices can achieve a good level of cervical spine extension. However, and especially when the readjustment is needed, these devices usually require additional efforts to achieve a careful positioning along with a safe control of the cervical spine by the anesthesiologist and the surgical team ${ }^{2}$. For that, the authors feel having a fix adjustable tool can enhance the degree of extension in a more controlled fashion which in turn will enhance the safety of the surgical procedure overall. In addition to that, the traditional devices intra-operatively do not allow an easy and

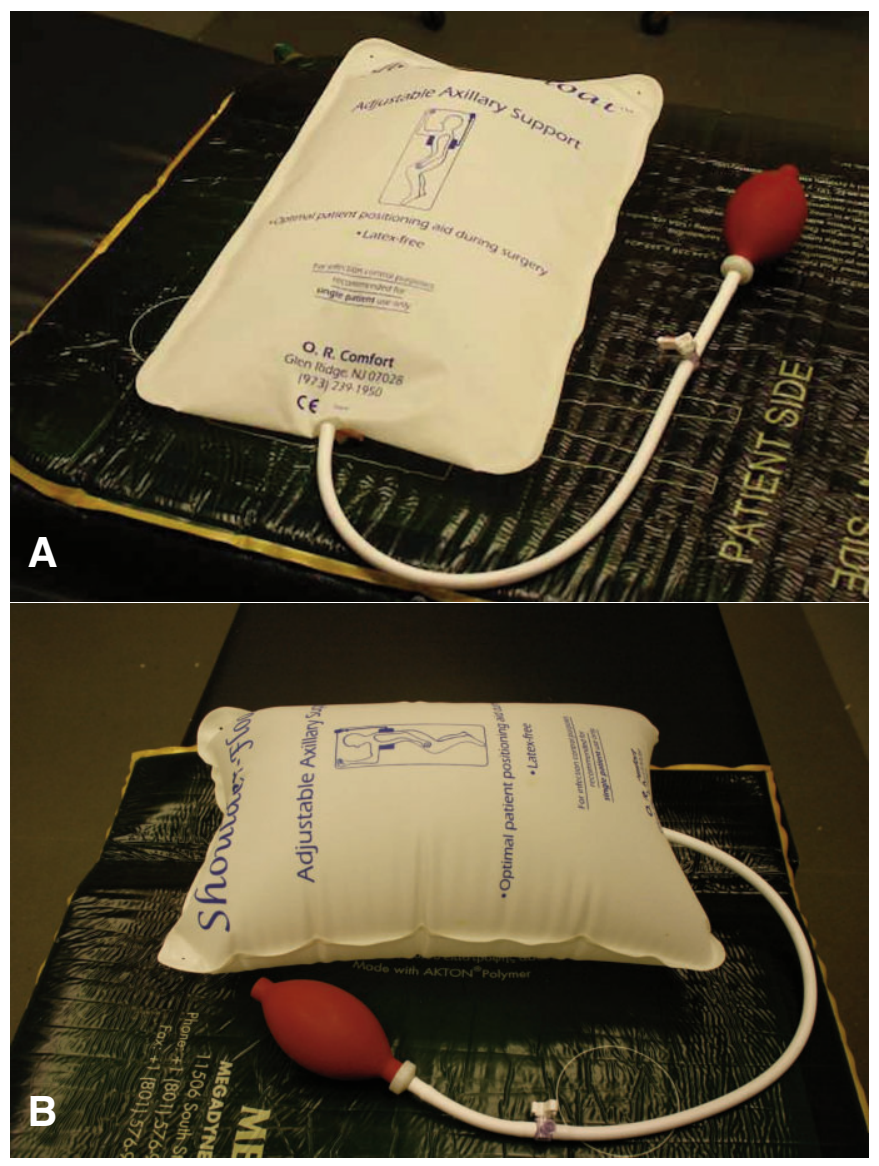

Figure 1: Shoulder Float Device (A\& B)

direct access to change the degree of neck extension comparing to shoulder float.

The control extension of the neck provided by the inflatable device allows for an excellent stability, and minimal movement

From the Division of Neurosurgery (WAA, ARA, KR), McMaster University, Hamilton; York University (MFS), Toronto, Ontario, Canada.

Received July 29, 2013. Final Revisions Submitted OCtober 10, 2013. Correspondence to: Waleed A. Alsunbul, Division of Neurosurgery, McMaster University, 7-7southside place, Hamilton, Ontario, L9C 7W6, Canada.

Email: waleed.alsunbul@medportal.ca. 


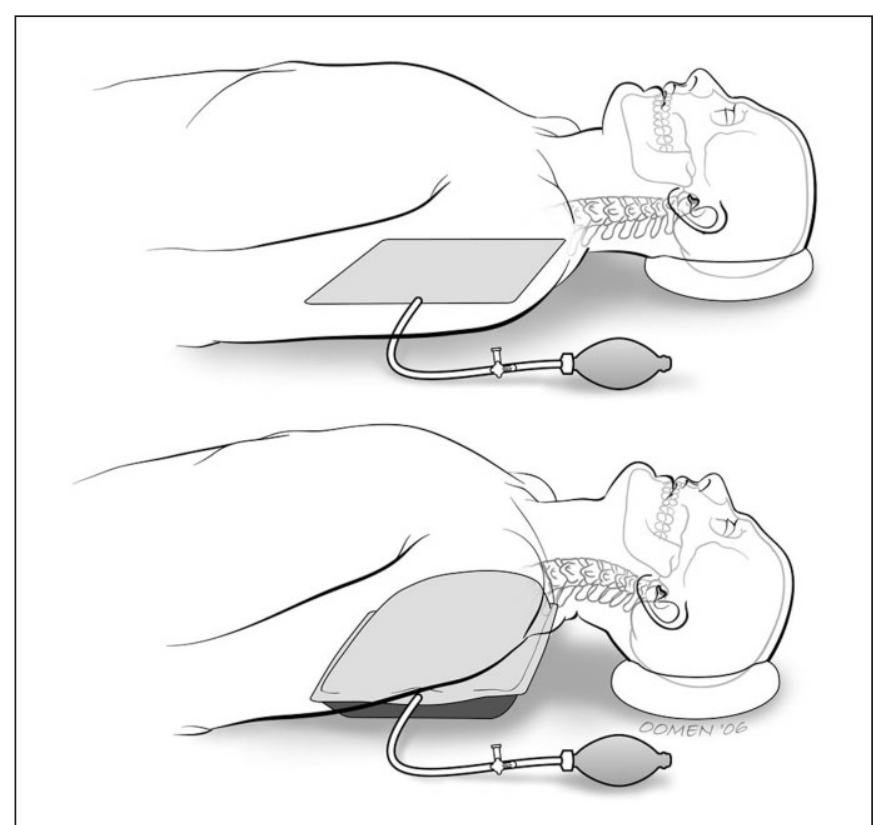

Figure 2: Schematic illustration showing the authors techniques to achieve cervical spine extension during surgery using Shoulder Float Device.arrowhead), external carotid arteries (black arrows), and vertebral arteries (white arrows). is required for an anesthetized patient undergoing spine surgery. Once it is beneath the shoulders of the patient, the device can be inflated or deflated as desired, with minimal movement of the cervical spine.

In some cases, such as anterior odontoid screw fixation for unstable type II odontoid fracture requires a particularly careful positioning of the cervical spine with a fair degree of the cervical spine extension ${ }^{3,4}$. This need to be achieved with the minimal possible movement of the cervical spine and the endotracheal tube, to avoid any potential damage to the spinal cord, at times with cervical traction device in place $^{5,6}$. In the case of retrolisthesis of the fracture fragment, realignment needs to be achieved and maintained before drilling and screw fixation can begin. Trying different sizes of bolsters or other devices along with checking the cervical spine position under fluoroscopy or lateral radiographs typically can achieve all of this. However, this usually lead to some degree of manipulation of the cervical spine which in turn could be associated with a higher chance to injure the spinal cord. The authors believe, with the shoulder float, the positioning will be more safe and simplified. We simply place the device horizontally under the shoulders with the upper edge of the device at the level with the shoulder line and inflate as needed under fluoroscopy with less manipulation of the cervical spine. In a randomized crossover study $^{7}$, use of inflatable device resulted in significantly less pressure beneath
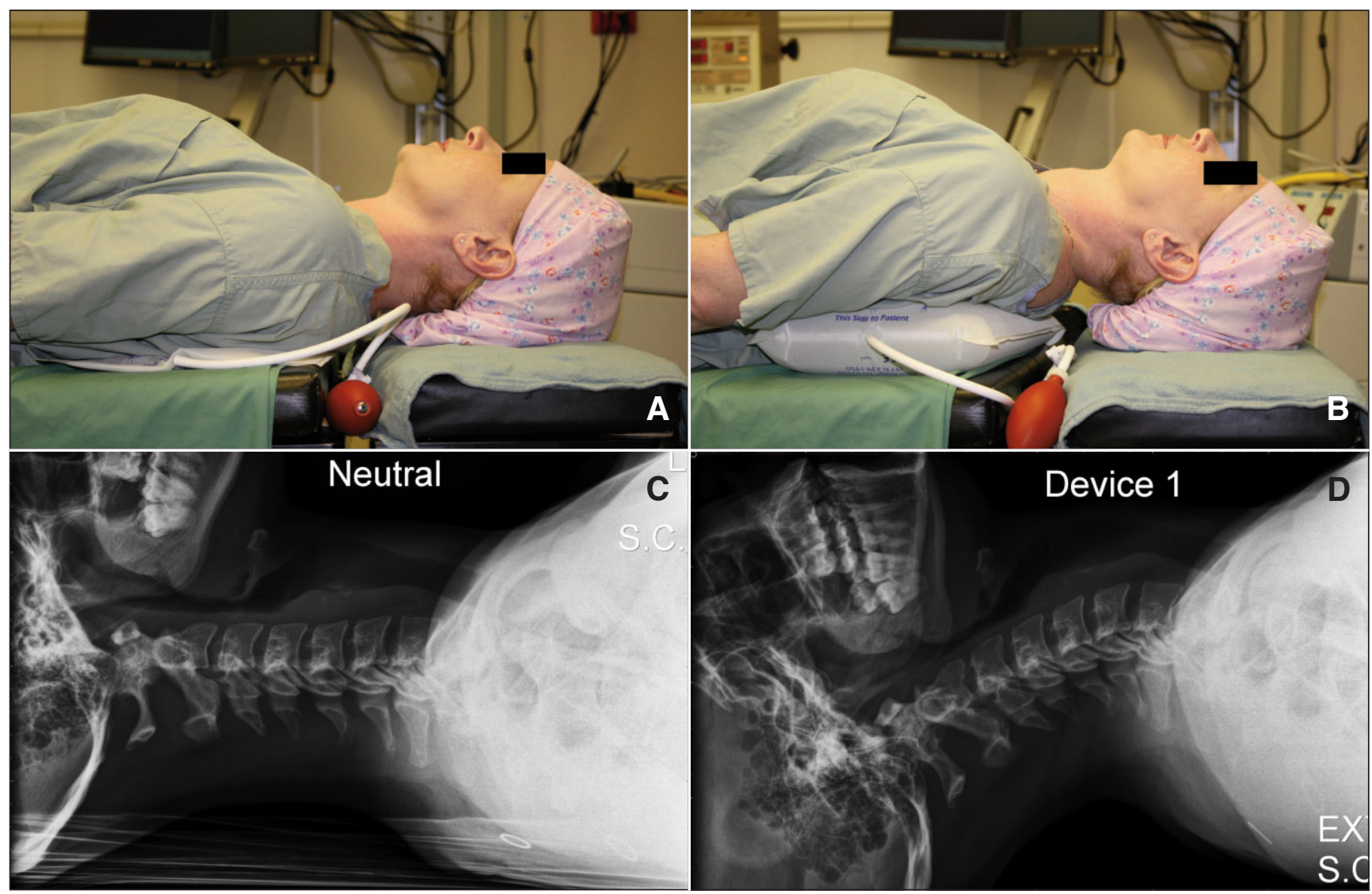

Figure 3: Simulating Intraoperative patient's position using the device with lateral plain x-ray of cervical spine demonstrating a good controlled degree of extension during deflation $(A \& C)$ and inflation of $(B \& D)$ Shoulder Float Device. 
the dependent shoulder and chest wall than either a gel-pad or a 1000-mL lactated Ringer's bag.

In the author's experience, the inflatable device seemed to be more convenient and useful as compared to the devices that are used for the same purpose. It can provide a good control and stable extension during surgery and allow the surgeon to have different degrees of extension intra-operatively with direct access and minimal movement of the cervical spine (Figure 3AD). We believe it reduces the intra-operative risk of worsening neurological function, though this is clearly subjective. It is inexpensive and reusable as long as care is taken not to perforate the bag, and the system is checked pre-operatively for air leakage. At times, especially in extremely thin patients, there is a tendency for the patient to roll on the device to one side. This, however, can easily be corrected by centring the inflatable device and reinforcing it by tape.

\section{Conclusion}

We have used this device in every anterior cervical spine surgery. We believe it is an inexpensive and easy to use device that can enhance, intraoperatively, the level of patient's safety with an excellent stability and well control extension compared to the standard devices that are for the same purpose.

\section{ACKNOWLEDGEMENT AND DEClaRation}

The authors would like to acknowledge the assisting of Ms.N. Khan in this project. There is no financial support gained in in conjunction with the submission of this technical report.

\section{REFERENCES}

1. Cooper P. Anterior Cervical Vertebrectomy: Tips and Traps. Neurosurgery. 2001 Nov; 49(5): 1129-32.

2. Raw DA, Beattie JK, Hunter JM. Anaesthesia for spinal surgery in adults. Br J Anaesth. 2003 Dec;91(6):886-904.

3. Morandi X, Hanna A, Hamlat A, Brassier G. Anterior screw fixation of odontoid fractures. Surg Neurol. 1999 Mar;51(3):236-40.

4. Alfieri A. Single-screw fixation for acute Type II odontoid fracture. J Neurosurg Sci. 2001 Mar;45(1):15-8.

5. Kılıç T, Goksu E, Durmaz D, Yıldız G. Upper cervical spine movement during intubation with different airway devices. Am J Emerg Med. 2013 Jul;31(7):1034-6.

6. Ernst E. Adverse effects of spinal manipulation: a systematic review. J R Soc Med. 2007 July; 100(7): 330-8.

7. Gonzalez Della Valle A, Salonia-Ruzo P, Peterson MG, Salvati EA, Sharrock NE. Inflatable pillows as axillary support devices during surgery performed in the lateral decubitus position under epidural anesthesia. Anesth Analg. 2001 Nov;93(5):1338-43. 